\title{
NOTE ON THE MICROSCOPIC DETECTION OF BEEF FAT IN LARD.'
}

\author{
By Thomas S. Gladding. \\ Received January 3, 1896.
}

I the preparation of crystals of lard and beef stearin for microscopic examination, I find the following method gives excellent results, the crystals being of good size and of distinctive form. Dissolve five cc. of melted lard in a mixture of ten cc. absolute alcohol and five cc. ether, in a small Erlenmeyer flask, heating gently if necessary. Place a plug of cotton in the mouth of the flask and allow to stand in a cool place for about half an hour. The stearin crystallizes out, the olein remaining in solution. Filter rapidly through a paper wet with alcohol, using a filter pump, and wash crystals and paper once with the above alcohol-ether mixture (10-5). Let the crystals dry in the air and remove them from the paper to the flask. Dissolve in twenty-five $c c$. of ether, replace the cotton plug, and place the flask in a slanting position in a large beaker (about one liter) nearly full of water. Keep this in a cool place over night. The ether evaporates very slowly and the crystals of stearin are gradually formed in the solution, the large quantity of water surrounding the ether solution guarding against any sudden change of temperature. For valuable plates giving characteristic forms of lard stearin crystals and beef stearin crystals reference is made to Bulletin No. I3, Part IV., Division of Chemistry, U. S. Department of Agriculture.

\section{NOTES.}

The Estimation of Levulose in Honey. - Through my negligence, I failed to call attention, on page $8 \mathrm{r}$ of the Jantuary number, to the optical method described by Allen, Commercial Organic Analysis, Vol. I, p. 29I, relating to the estimation of levulose by changes in the specific rotatory power due to variations of temperature.

H. W. WILEy.

A New Balance for First Year's Work in General Chemistry. -The little balance shown in the cut was designed for the use

1 Read at the cleveland meeting, December 3I, I895. 
of my students in their first year's laboratory practice, and has served its purpose so well in two large classes that I venture to call attention to it in the hope that others may find in

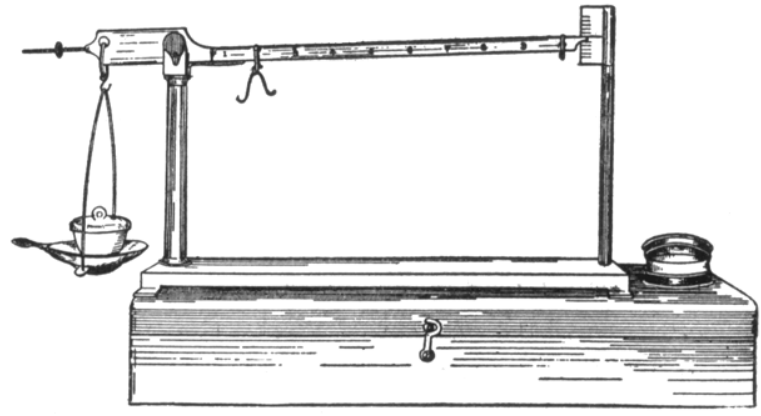

it a satisfactory solution of the balance problem in their schemes of beginners' laboratory work.

It is simple, efficient, and not expensive. The posts and beam are of lacquered brass; the base of iron. The length of the beam is twelve inches. The riders are of three weights, equivalent, when at the first division of the long arm, to r.ooo, o. Ioo and o.oro gram respectively in the pan. Thus, in the cut, the weight of the crucible is I 2.230 grams. The balance is sensitive to 0.010 with a load of 30.000 grams, and to 0.005 gram with a smaller load. Adjustment to zero before weighing is effected by means of a nut at the end of the short arm. It may be obtained of Messrs. Richards \& Co., of New York.

JOHN TAPPAN STODDARD.

\section{NEW BOOKS.}

Analytical, Chrmistry. By N. Mrnschutkin, Professor in the University of Str. Pletersburg. Translated from the Third German Edition, under the Supervision of the Author, by James Locke. London and New York: Macmillan \& Co. 5I2 pp. Price $\$ 4.00$.

Although the plan of treating the whole subject of analytical chemistry, qualitative and quantitative, in one volume has obvious merits, it is nevertheless something of a novelty, in this country at least, and on this and many other accounts this translation of Professor Menschutkin's work is very welcome. 